NASA Technical Memorandum 102611

\title{
EVALUATION OF AN ADAPTIVE UNSTRUCTURED REMESHING TECHNIQUE FOR INTEGRATED FLUID-THERMAL-STRUCTURAL ANALYSIS
}

\section{PRAMOTE DECHAUMPHAI}

FEBRUARY 1990

(NASA-TM-10?O11) EVALUATIUN DF AN ADAPTIVE UNSTRULTUREO REMESHING TECHNIQUE FOR INTEGRATED FLUID-THERMAL-STRUCTURAL ANALYSIS (NASA) $13 \mathrm{D}$

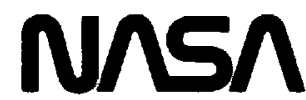

National Aeronautics and Space Administration

Langley Research Center Hampton, Virginia 23665
$N 90-2 \overline{0426}$

Unclas

0271138 


$$
\cdots
$$




\title{
EVALUATION OF AN ADAPTIVE UNSTRUCTURED REMESHING TECHNIQUE FOR INTEGRATED FLUID.THERMAL-STRUCTURAL ANALYSIS
}

\author{
Pramote Dechaumphal \\ NASA Langley Research Center \\ Hamplon, Virginla
}

\begin{abstract}
An adaplive unstruclured remeshing technique is evaluated for integrated fluid-thermal-structural analysls. The technique is combined with the finite element method to solve: (1) the Navier-Slokes equations lor high-speed compressible llow, (2) the energy equallon for the structural-thermal response, and (3) the quasistatic equilibrium equations for the structural response. The remeshing technique and the analysis solution procedure are described. The effectiveness of the approach is evaluated with two application studies. The llow analysis of Mach 8 shock-shock interference on a three-Inch-diameter cyllnder is used as the first application study to demonstrate the capability of the remeshing technique and to examine proper remeshing Indicators for the inviscid and boundary layer reglons. The applicablity of the approach for the thermal and structural analyses of the structure is evaluated in the second appllcation study of a 0.25 -Inch-dlameter convectively cooled leading edge subjected to intense aerodynamic healing. Issues assoclated with remeshing indicators for thermal stress problems are Identified.
\end{abstract}

\section{Nomenclature}

A

element area, Eq (10)

[A'] Jacoblan matrix, Eq. (8)

[B] viscous flux matrix, Eq. (11)

C

E, $F \quad x$ and $y$ flux components

H load vector, Eq. (3)

h conveclive heat transfer coefficlent, Eq. (5),

(11 or element spacing parameter, Eq. (22)

IK] $\quad$ identity malrix

$k$ thermal conductivity

I, m components of unit normal veclor

m coolant mass flow rate

[M] mass matrix

[N] element interpolation or welghting function

$\bar{n} \quad$ unit normal vector

P coolant passage perimeler

p pressure

q heat flux

(A) load vector

s edge length of finite element

$T$ temperature

To reference temperalure for zero stress

1 lime

U conservation variable

$u, v \quad$ flow velocity components, Eq. (2), or

displacement components, Eq. (19)

\footnotetext{
'Aerospace Technologisi, Aerolhermal Loads Branch, Structural Mechanics Division, Member AIAA
}

\begin{tabular}{|c|c|}
\hline $\begin{array}{l}x, y \\
X, Y\end{array}$ & $\begin{array}{l}\text { coordinate direclions } \\
\text { principal coordinate directlons }\end{array}$ \\
\hline$\Delta t$ & Uime step \\
\hline$\Delta \mathbf{U}$ & $u^{n+1}-u^{n}$ \\
\hline $\begin{array}{l}\beta \\
8\end{array}$ & $\begin{array}{l}\text { thermal expansion parameter } \\
\text { boundary layer thickness }\end{array}$ \\
\hline E & $\begin{array}{l}\text { flow total energy. Eq. (2), or st } \\
\text { componenis, Eq. (18) }\end{array}$ \\
\hline$\lambda$ & elgenvalues \\
\hline$\phi$ & key parameter for remeshing, \\
\hline$\rho$ & density \\
\hline$\sigma_{x}, \sigma_{y}, \tau_{x y}$ & $\begin{array}{l}\text { fluld stress components, Eq. (2) } \\
\text { stress components, Eq. (7) }\end{array}$ \\
\hline \multicolumn{2}{|c|}{ Subscripts } \\
\hline$F$ & fluld \\
\hline $\begin{array}{l}\mathbf{L} \\
\mathbf{A}\end{array}$ & $\begin{array}{l}\text { leit element } \\
\text { rlght element }\end{array}$ \\
\hline $\mathbf{T}$ & thermal \\
\hline $\mathbf{s}$ & siructural \\
\hline 1 & element internal llux \\
\hline 2 & flux across element boundary \\
\hline \multicolumn{2}{|c|}{ Superserlpls } \\
\hline I & inviscid \\
\hline v & viscous \\
\hline $\mathrm{T}$ & Iranspose \\
\hline 1,1 & summallon Indices \\
\hline
\end{tabular}

\section{Introduction}

Design of lightweight structures and thermal protection systems for hypersonic vehicles depends on accurate predlcilon of aerothermal loads, siructural temperalures and their gradients, and structural deformations and stresses. Adaptive unstructured remeshing techniques combined with the finile element method have been shown to improve significantly the efficlency and accuracy of the flow analysis. These benefits should accrue for both the thermal and structural analyses of structures. In addition, a unlversal remeshing procedure is needed for the development of an Integrated fluld-thermal-structural analysis capability.

Research is currently underway at NASA Langley Pesearch Center to develop an Integrated analysis approach for accurately predicting each disciplinary behavlor and their Interactions. The approach uses the finlte element method to solve: (1) the Navier-Stokes equations for the aerodynamic flow fleld and the aerothermal loads; (2) the structural energy equation tor heat Iransfer and temperature distribution; and (3) the structural equilibrium equations for delormation and stresses. The capabillty of the approach was demonstrated lor an undisturbed Mach 6 flow over a 
three-inch-diameter stainless steel cylinder ${ }^{1}$ for which the experimental data 2 were avallable for comparison. the flow field is characterized by the bow shock that stands-off the cylinder and the thin boundary layer at the cyllnder surtace. Sharp gradients in the flow variables occur in these reglons and closely spaced elements were generated manually to model these llow features. The flow solution compares well with the experimental data demonstrating the ellectlveness of the linite element method used.

For a more complex problem, where a prlorl knowledge of the flow physics does not exist, an approprlate finite element mesh may not be constructed easily. An edaptive mesh generatlon lechnique is required not only to construct and adapt the mesh automatically to represent the llow fleld but also to reduce the number of unknowns and the analysis computational time. Thus the current focus on the Improvement of the integrated analysis approach is to develop efficient adaptive unstructured mesh generation techniques for each analysis discipllne considered including their interlace requirements.

Adaptive mesh generation techniques may be classilled Into two major categories: (1) refinement/derefinement, and (2) remeshing. The first category, the adaptive reflnement/derefinement technique, can be further classified into three subcategorles: (a) the $h$ method, (b) the p method, and (c) the $r$ method. In the $h$ method, the elements in the inlilal mesh are reflned into smaller elements or derefined into larger elements 3 . The p method maintains the geometry of the elements of the Initial mesh but increases (or decreases) the order of the polynomial used for the element interpolation funclion4. The $r$ method keeps the number of elements and their conneclivities the same but relocates the nodes 5 . These methods help Increase the analysis solution accuracy but each has limitations. Even though nodes could be added or removed by the $h$ method, the orlentation of the original and new elements does not change. Orientation of element sides along princlpal flow gradients Increases solution accuracy and reduces the number of elements 6 . Even though the $r$ method can move the nodes for belter allgnment, the method may generate hlghly distorted elements II the number of elements is fixed. The $p$ method may allevlate these restrlctlons because of the llexibility. In selectling the order of polynomials on the element sides. However, the use of such higher order polynomlals in combination with the hlerarchical concept leads to complextlies in the formulation of finite element equations and Implementation In computer programs.

The above considerations led to the development of the second adaptive mesh category, the remeshing lechnique7. The lechnique generates an entirely new mesh based on the solution oblained from the earlier mesh. The technique combined with the finile element method has been applied successfully to several compressible flow problems with complex llow behavior 8,9 . The purpose of this paper is to extend the adaptive remeshing lechnlque to both the thermal and structural analyses of structures. The edaptive remeshing technique will be evaluated to assess its elfectiveness for the integrated lluid-thermal-siructural analysis. The governing equallons for the aerodynamic flow, struclural heat transter, and structural response will be introduced first. The finlte element solution algorithms for solving these equations will be described. basic concepts of the adaptive remeshing technique will then be explained. Selection of Indlcators used for constructlon of new meshes for the three analysis disclpllnes will be discussed. Finally the edaptive remeshing technique will be evaluated for: (1) the lluid analysis of Mach B shock-shock Interlerence on a threeInch-dlemeler cyllnder where the experimental data is avallable, and (2) the thermal-structural analysis of a 0.25 -Inch-dlameler convectlvely cooled leading edge subjected to Intense aerodynamlc healing simulating Mach 16 tlight condition. The issues of mesh continuity along the fluid/structure Intertace and belween thermal and siructural analyses for direct Interdisciplinary data transfer will also be discussed.

\section{Integraled Fluld-Thermal-Structural Procedure}

\section{Governing Equations}

Aerodynamle Flow. The equations for a laminar compressible flow are governed by the conservation of mass, momentum, and energy. These equations are written in conservation form as

$$
\frac{\partial}{\partial t}\left\{U_{F}\right\}+\frac{\partial}{\partial x}\left\{E_{F}\right]+\frac{\partial}{\partial y}\left[F_{F}\right]=0
$$

where the subscript $F$ denotes the fluld analysis. The conservalion variables vector, $\left(U_{F}\right)$, and the flux vectors in the $x$ and $y$ directions, $\left(E_{F}\right)$ and $\left(F_{F}\right)$, are given by

$$
\begin{aligned}
& \left(U_{F}\right)^{T}=\left[\begin{array}{llllll}
\rho & \rho & \rho & \rho
\end{array}\right.
\end{aligned}
$$

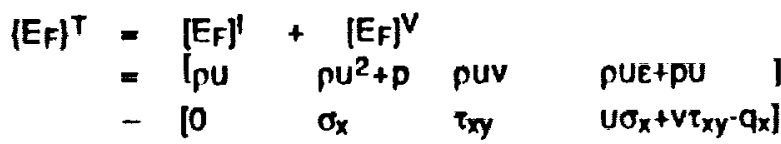

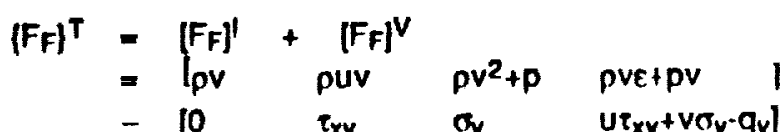

Superscripts 1 and $v$ represent the inviscid and viscous liux vector components, respectively. The pressure $p$ is related to the tolal energy assuming a calorically pertect gas (constant ratio of specific heats). The stresses $n_{x}$, $\sigma_{y}$, and $\tau_{x y}$ are related to the velocity gradients by Stokes' hypothesls. The heat fluxes $q_{x}$ and $q_{y}$ are related to the temperature gradients by Fourier's law. The temperature-dependent viscosity is computed from Sutherland's law and the thermal conductivity is computed assuming a conslant Prandll number of 0.72 .

Siructural Heat Transter. The thermal response of the structure is governed by the energy equation which is written in conservation form as

$$
\frac{\partial}{\partial t}\left(U_{T}\right)+\frac{\partial}{\partial x}\left(E_{T}\right)+\frac{\partial}{\partial y}\left(F_{T}\right)=H_{T}
$$

where the subscript $T$ denotes thermal analysis. For translent heat conduction, the conservation variable, $U_{T}$, and the heat flux components, $E_{T}$ and $F_{T}$, are 


$$
\begin{aligned}
& d U_{T}=\rho_{3} c_{8} d T_{5} \\
& \begin{array}{llll}
E_{T} & =q_{x} & = & -k_{0} \frac{\partial T}{\partial x} \\
F_{T} & =q_{y} & = & -k_{0} \frac{\partial T}{\partial y}
\end{array}
\end{aligned}
$$

and $H_{T}$ is the heat source. The structural heat flux components $q_{x}$ and $q_{y}$ are related to the temperature gradients by Fourier's law.

For a structure with internal convection cooling. the energy equation for the coolant flow in the local $x$. direction based on assumed uniform cross-sectional or bulk temperature 1 can also be written in the conservation form of Eq. (3) where

$$
\begin{aligned}
d U_{T} & =\rho_{F} c_{F} T_{F} \\
E_{T} & =\dot{m} c_{F} T_{F} / A_{F} \cdot k_{F} \partial T / \partial x \\
F_{T} & =0 \\
H_{T} & =h P\left(T_{:}-T_{F}\right)
\end{aligned}
$$

The flux $E_{T}$ consists of the energy transport by convection (1st lerm) and conduction (2nd term), and the flux $\mathrm{H}_{\mathrm{T}}$ represents the heat transter between the structure and the coolant.

Struclural Response. The structural response is governed by the quasi-static equilibrium equalions assuming that the inerlia ellect is negliglble. These equations are written in conservation form as

$$
\frac{\partial}{\partial x}\left(E_{s}\right)+\frac{\partial}{\partial y}\left(F_{s}\right)=0
$$

The flux vector components, $\left(E_{s}\right)$ and $\left\{F_{s}\right\}$, are

$$
\begin{aligned}
& \left\{E_{8}\right\}^{\top}=\left[\begin{array}{ll}
\sigma_{x} & \tau_{x y}
\end{array}\right] \\
& {\left[F_{g}\right]^{\top}=\left[\begin{array}{ll}
F_{x y} & \left.\sigma_{y}\right\rfloor
\end{array}\right.}
\end{aligned}
$$

where the stress componenls, $\sigma_{x}, \sigma_{y}$, and $\tau_{x y}$ are related to the displacement gradients and the temperalure by generalized Hooke's law.

\section{Finite Element Solution Algorilhms}

An Implicitexpllcil upwind cell-centered algorithm 9,10 is used to solve the Navier-Stokes equatlons, Eqs. (1)-(2). A flux-based Taylor-Galerkin finlte element algorithm 9.11 is used to solve the thermal and structural equations, Eqs. (3)-(7). For brevily, only essential features of the algorithms are highlighted herein.

Upwind Fluld Algorlthm. The basic concept behind the upwind cell-centered algorithm is to delermine the flux across element Interfaces by Roe's averaging procedure 12. The average Inviscld flux $\bar{E}^{\prime}$ the "overbar" denotes an average quantity normal to the element interlace belween the left element, $L$, and the right element, A) Is given by

$$
\bar{E}^{j}=\frac{1}{2}\left[\bar{E}_{L}^{i}+\bar{E}_{R}^{\prime}+\left|A^{*}\right|\left(U_{L}-U_{R}\right)\right]
$$

where $\left|A^{*}\right|$ denoles the absolute Jacoblan malrix associated with the element llow velocity components and the local speed of sound. Details of the Jacobian matrix $A^{*}$ are given in Rel. [12].

In the computation of viscous llux components such as the heat flux in the $x$-direction $\left(q_{x}=-k_{F} \partial T / \partial x\right)$. the element temperalure gradient is computed from

$$
\frac{\partial T(x, y)}{\partial x}=\{N(x, y)]\left\{\frac{\partial T}{\partial x}\right\}
$$

where $[N(x, y)]$ is a malrix of finite element inlerpolation functions. The vector on the right hand side of the equation contains the nodal temperature gradienls. determined at node $\mathrm{K}$, by

$$
\frac{\partial T}{\partial x} I_{K}=\frac{1}{M_{K}}-\left(\int \bar{n} T N_{K} d s-\int_{A} T \frac{\partial N_{K}}{\partial x} d A\right)
$$

where $\bar{n}$ is the unit normal vector along the element interface $s$ and $M_{K}$ is the lumped mass at node $K$.

Increments in lime of the element conservation variables, $\Delta U=U^{n+1} \cdot U^{n}$, are determined from

$$
\begin{aligned}
{\left[[I]+\frac{\Delta t}{A} \sum\right.} & \left.\left.\left(\mid A^{*}\right] \frac{s}{2} \cdot[B]\right\rangle\right] \Delta U \\
& =\cdot \frac{\Delta t}{A} \xi s\left[\bar{E}^{\prime}+\vec{E}^{V}\right]
\end{aligned}
$$

The matrix [B], which is associated with the viscous fluxes is given in Ref. [10], accelerates the solulion convergence in the viscous dominaled regions. This fluid algorithm provides first order of accuracy $(O(h))$ in the Inviscid flow dominated region but the order of accuracy is close to $1.5\left(O\left(h^{1.5}\right)\right)$ in the viscous flow dominated reglon 10 .

Flux-Based Taylor-GalerkIn Algorlthm. The basic concept of the flux-based Taylor-Galerkin e'zorithm is to express the element flux components $E$ and $F$ In the form

$$
E(x, y, t)=[N(x, y)](E(1)\}
$$

where $(E)$, and $(F)$ are vectors of the element nodal flux quantities.

For the thermal analysis, the final finite element equations are in the form

$$
[M]\left(\Delta U_{T}\right)^{n+1}=\left(R_{T}\right)_{1}^{n}+\left(A_{T}\right)_{2}^{n}
$$

where at lime $n+1, \Delta U^{n+1}=U^{n+1} \cdot U^{n}$. The mass matrix. [M], Is determined from

$$
[M]=\int_{A}[N][N] d A
$$

The two vectors on the right hand side of Eq. (13) are associated with the fluxes within the element (subscript 
1) and across the element boundary (subscript 2). These vectors are defined by

$$
\begin{aligned}
& \left(R_{T}\right)_{1}^{n}=\Delta t\left(\int_{A}\left(\frac{\partial N}{\partial x}\right)(N) d A \mid E_{T}\right)^{n} \\
& \left.+\int_{A}\left(\frac{\partial N}{\partial y}\right)|N| d A\left(F_{T}\right)^{n}\right) \\
& \left(R_{T}\right)_{2}^{n}=-\Delta t \int_{s}\{N][N] d s\left(\mid\left(E_{T}\right)^{n}+m\left(F_{T}\right\}^{n}\right) \\
& =-\Delta t \int_{3}(N)[N] d s(q)^{n}
\end{aligned}
$$

The vectors $\left\{E_{T} \mid\right.$ and $\left\{F_{T}\right\}$ contain nodal heat fluxes which depend on the nodal temperalure gradients. The element nodal temperature gradients $\partial T / \partial x$ and $\partial T / \partial y$, and all the finite element matrices (Eqs. (13)-(16)) can be evaluated in closed form (l.e., numerical integralion is not required) for any type of finite elemenls including the 4-node quadrilateral and the 8-node hexahedral elements.

For the struclural analysis, the final finile element equations are in the same form as the thermal equation. Eq. (13), but without the transient term,

$$
\left|R_{3}\right|_{1}+\left|R_{3}\right|_{2}=0
$$

where these vectors are Identical to Eqs. (15)-(16) except that the subscript $T$ is replaced by the subscript s everywhere. The element nodal flux vectors $\left\{\bar{E}_{s} \mid\right.$ and [Fs) (similar to $\left(E_{T}\right\}$ and $\left\{F_{T}\right\}$ in Eq. (15)) now consist of the stress components $\sigma_{x}, \sigma_{y}$ and $\tau_{x y}$. By using the thermal siress-strain constilutive relations,

$$
\sigma_{1}=c_{11} \varepsilon_{1}+\beta_{1}\left(T-T_{0}\right) \quad l, J=1,2,3
$$

and the strain-displacement relations, these nodal stress components associated with the $\left\langle\mathrm{R}_{\mathrm{a}}\right\rangle_{1}$ vector can be written in terms of the nodal displacement components. Further algebralc manipulation of the finite element equation, Eq. (17), results In the standard form of

$$
\{K]\{U\}=\left\{R_{1}\right\}_{2}+\left\{R_{T}\right\}
$$

where (U) consists of the unknowns of the nodal displacement components, $[K]$ is the element stiflness matrix, and $\left[R_{T}\right]$ is the thermal load veclor. These matrices are evaluated in closed lorm and the delalls are given in Rol. [11].

\section{Adaptlve Remeshing Procedure}

\section{Remeshing Concepl}

The basic idea of adaptive remeshing is to construct a completely new mesh based on the solution obtained from the previous mesh. The new mesh will consist of clustered elements in regions with large solution gradients and lew elements in the regions where the gradients are small. Element orientations are In princlpal directlons to provide the most accurate solution with a minimum number of elements. As an example, the shorter element side is In the direction normal to the shock line or through the boundary layer thlckness to model large solution gradienls. Based on these ideas, the adaplive remeshing technlque consists of two steps: (1) the determination of the new element sizes and their orlentations, and (2) the construction of the new mesh.

In the determinalion of the element size and orientation, the solid mechanics concept of determining the principal stresses and their directions from a given slate of stress at a point is employed. For example in the thermal analysis, small and clustered elements are needed in reglons of large temperature gradients. The temperature is thus considered as a key parameler to indicate where clustered elements are needed. Al a typlcal node in the old mesh, the second derivative 10 of the key parameler with respect to the global coordinales $x$ and $y$ are first computed.

$$
\left[\begin{array}{cc}
\frac{\partial^{2} \phi}{\partial x^{2}} & \frac{\partial^{2} \phi}{\partial x \partial y} \\
\frac{\partial^{2} \phi}{\partial x \partial y} & \frac{\partial^{2} \phi}{\partial y^{2}}
\end{array}\right]
$$

where $\phi$ denotes the key parameter used for remeshing. Then the elgenvalues which represent the principal quantilies in the principal directions $X$ and $Y$ where the cross derivatives vanish are determined.

$$
\lambda_{1}=\left|\frac{\partial^{2} \phi}{\partial \mathrm{X}^{2}}\right| \text { and } \lambda_{2}=\left|\frac{\partial^{2} \phi}{\partial \mathrm{Y}^{2}}\right|
$$

These elgenvalues are the remeshing indicalors and are used to determine the element spacings $h_{1}$ and $h_{2}$ in the two princlpal directlons using the condition of

$$
h_{1}^{2} \lambda_{1}=h_{2}^{2} \lambda_{2}=\text { constant }
$$

which has been shown to distribute the solution error equally, a condilion for an optimal mesh ${ }^{13}$. This process is pertormed for all the nodes in the old mesh leading to the final condition 7 of

$$
h_{1}^{2} \lambda_{1}=h_{2}^{2} \lambda_{2}=\text { constant }=h_{\min }^{2} \lambda_{\max }
$$

Using this condition and specilying the required minimum element spacing $h_{m} i n$, the new element spacings based on the solution of the old mesh are oblained and the new mesh is constructed.

Mesh construction is based on an advancing Iront technique 7 . Nodes are first placed along the domain boundary. Spacings belween these nodes are dictaled by the olement spacing parameter $h$ obtained earlier. At this instance, the front consists of a sequence of stralght line segments which connect conseculive boundary nodes. I.e., the domain boundary. Elemenls adjacent to the domain boundary are then constructed. The slzes and orlentations of these elements are gulded by the computed element spacing parameter $h$ and the principal directions. As new elements are constructed from the domain boundary, the front is updated and represented by the new element sides. As the mesh consiruction goes on, the tront changes its shape continuously and propagates loward the domain interior. The generation 
process is terminated when the domain is fllled completely with elements and the front vanishes.

Based on the condition shown in Eq. (23), the element size is generaled according to the given minlmum element spacing $h_{m i n}$. Specifying too small a spacing $h_{\min }$ could result in a model with a large number of elements which may be impracilcal to perform the analysis. On the other hand, specifying too large a spacing $h_{\mathrm{m}}$ in may result In an Inadequate analysls solution accuracy, or excessive analysis and remeshing cycles to achleve the required solution accuracy. These factors must be considered prlor to generating a new mesh. Note that, because the technique generates an entirely new mesh with different nodal locations from the old mesh, interpolation of the solution from the old to the new mesh is necessary. The Interpolaled nodal quantities are used as the initial condilions for the new mesh to increase the analysis solution convergence.

\section{Fluld-Thermal-Structural Femeshing Parameters}

The adaptive remeshing technique described requires a selection of proper key paramelers ( $\phi$ in Eq. (20)) for remeshing so that generated elements are clustered where needed. Selection of the key parameters depends on the analysis discipline and its applications. For thermal problems, it is obvious that the temperature should be used as the key parameler so that the mesh generated can represent steep temperalure gradients. For struclural problems, stress is an appropriate cholce for the key parameter so that regions with high stress concentration will be represented. However, the key parameler representing the stress should be a scalar quanlity such as the Von Mises stress defined by,

$$
\sigma_{\text {Von Mises }}=\frac{1}{\sqrt{2}} \sqrt{\left(\sigma_{x} \cdot \sigma_{y}\right)^{2}+\sigma_{x}^{2}+\sigma_{y}^{2}+6 t_{x y}^{2}}
$$

Note that the key parameter selected for remeshing may vary with applications. For problems that require accurate deformations rather than the stresses, an absolute displacement quantity may be preferred as the key parameter.

For high-speed compressible flow problems. selection of the proper key parameters for remeshing may be more difficult. In the inviscid flow fleld, the fluld density is normally selected as the key parameter 9 because densily exhibits high gradients across shock and flow expansion waves. In the viscous dominated flow regions, such as the boundary layer, other key parameters may be more appropriate. Key paramelers of heating rate and skin friction may be used for more accurate analysis prediction of the aerothermal loads. The selection of these key paramelers for remeshing in the three different analysis disciplines will be discussed in detail in the next section.

\section{Evaluatlon of Integrated Analysis and Adaptlve Remeshing Procedures}

Two applications are presented to assess the adaptive unstruclured remeshing procedures lor integrated fluid-thermal-structural finite element analysis. The fluid analysis of Mach 8 shock-shock inlerterence on a three-inch-diameter cylinder is used as the first application to Illustrate the successful implementation of the adaptlve remeshing technique for complex flow and to Investigate the meshing issues for the integrated fluidthermal-structural model. The applicability of the remeshing technlque tor thermal and structural problems is demonstrated in the second application for a 0.25 inch-diameter convectively cooled leading odge subjected to intense aerodynamic heating. Remeshing parameters for thermal and mechanical stress predictlons are Identifled.

\section{Mach 8 Shock-Shock Interterence On Cyllnder}

Leading edges of hypersonic vehlcles that experience intense stagnation point pressures and healling rales are a significant challenge to the designer. For englne leading edges, such as the cowl shown in Fig. 1, intense aerothermal loads occur when the cowl bow shock is intersected by an oblique shock resulting in a supersonic jet that impinges on the leading edge surface. The experimental configuration llower left ol Fig. 1), which simulates the vehicle forebody and cowl leading edge, was used to deline the aerothermal loads2.14. The experimental configuration is rotated $180^{\circ}$ relative to the vehicle. The schlleren photograph shows the supersonic jet interference pattern impinging on the surface of the cylinder. The interference pattern produces intense local amplification of the pressure and heat transfer rale in the vicinity of the jet Impingement. The undisturbed (absence of incident oblique shock and interterence pattern) stagnation pressure and healing rate can be ampllited by factors from 6 to 30 depending on the shock strength and the free stream Mach number 2,14.

The flow Interaction pattern superimposed on the llow computational domain and the three-inch-diameter cyllnder is shown schematically in Fig. 2. The inflow conditions above and below the obllque shock are: (1) Mach 6.03 flow at an angle of attack of zero degrees $\left(\alpha=0^{\circ}\right)$ and static temperalure of $200^{\circ} \mathrm{R}$, and (2) Mach 5.25 flow at an angle of altack of 12.5 degrees $\left(\alpha=12.5^{\circ}\right)$ and a statlc temperature of $430^{\circ} \mathrm{R}$. The supersonic jet Implinges on the cylinder surface approximately 22 degrees below the cylinder horizontal center line.

A first mesh shown in Fig. 3 is generated using a background mesh concepl described in Ret. [7]. A tolal of $\mathbf{4 1 9 2}$ trlangles are generaled in the inviscid region and 1568 quadrilateral elements in the boundary layer. The reasons for using quadrilateral elements in the boundary layer will be described in detail below. Using this mesh, the fluid analysis is pertormed to oblain a flow solution as illustrated by the Mach number contours shown in Fig. 4. Based on this llow solution and the use of the fluid density as the key parameler for remeshing, the second mesh is created as shown in Fig. 3. The flow solution oblained from the first mesh is then inlerpolated and used as the Initial condition for the second mesh. The same procedure is repeated on the subsequent meshes until the converged flow solution is achleved (a lotal of three meshes In this case).

The Mach number contours shown in Fig. 4 demonstrate the Improvement of the solution quality with the adapted meshes. The Mach number distrlbution obtalned from the third mesh shows improved sharpness of the shock Interterence paltern. The contours show a supersonic let (Mach number - 2) submerged within the subsonic regions belween the bow shock and the cyllnder. The supersonic llow in the jet lerminates 
through a nearly normal shock prior to Impinging on the cylinder surface.

The analytically predicted surlace pressure distribution from the third mesh is compared with the experimentally measured pressures ${ }^{2}$ in Fig. 5 . The predicted and experimental pressures are normalized by the undisturbed stagnation pressure ( $p_{0}=10.61$ psia). Good agreement between the analytical and experimental results are obtained for the pressure distribulion, the peak pressure and lis localions. Delails of the finite element mesh and the flow temperalure in the interaction region are shown in Fig. 6 . On both sides of the supersonic jet, the fluid lemperature increases abruptly across the bow shocks Irom a relatively low temperature (200 ${ }^{\circ} \mathrm{A}$ and $430^{\circ} \mathrm{A}$ ) to epproximately 2,700 'R. The temperature gradients in the shock layer (reglon between the bow shock and the cyllnder) are relatively small except in the thin boundary layer where the temperature drops sharply to the cyllnder surface temperature of $530^{\circ} \mathrm{R}$. Inside the supersonic jet, the fluid temperature increases slighlly from the free stream temperature to approximalely 1,000 \%. As the jel stream approaches the cyllinder surface, the fluid temperalure Increases abruptly across the jet normal shock to approximalely $3,000^{\circ} \mathrm{R}$ in a small slagnation reglon next to the cylinder surtace and drops sharply to the cyllinder lemperature of $530{ }^{\circ} \mathrm{R}$ resulting In hlgh aerodynamic healing rates.

The major difficulty in the fluid analysis is the prediction of the aerodynamic heating rates because a very accurate resolution of the flow temperature gradient normal to the cylinder surface is required. For the undisturbed Mach 8 flow, the predicled stagnation heating rate of approximately $42 \mathrm{Btu} / \mathrm{H}^{2}$-sec, which was obtained trom a finite element solution 1 and a viscous shock layer solution 15 , Is lower than the experimental value of $61.7 \mathrm{Btu} / \mathrm{ft}^{2}$-sec (Rel. [2]). The predicted and the experimental Interference heating rates are, therefore, normalized by their respective undisturbed stagnation point heating rates and are compared in Fig. 7. The heating rate distributlons are similar and the peak heating rate locations agree. However the predicled peak heating rate amplillcation is about $60 \%$ of that measured from the experiment. This difference may be attributed to several sources including the finlte element mesh, the analysis algorithm, and the mathematical model. The finite element mesh near the boundary layer may be Inadequate to represent the steep lemperature gradients accurately. The flow analysis algorithm, Eqs. (8)-(11). provides an accuracy on the order of the element characteristic length $h$ raised to the 1.5 power $\left(O\left(h^{1.5}\right)\right)$. In addition, the fluid flow mathematlcal model does not account for any turbulence. As discussed in Ref. 2, the higher experimental heating rate may be attributed to free stream turbulence in the fest stream which emanates from (1) the turbulent boundary layer on the nozzle and/or (2) shear layers that separate the supersonic jef from the subsonic reglons.

As mentioned earller, layers of quadrilateral elements are used in the boundary layer. Delall of these quadrllateral elements are shown in Fig. 8. The use of a structured mesh of quadrilateral elements in the boundary layer provides several advantages in the flow analysis. One advantage is that slender (hlgh aspect ratlo) elements can be used with their longer sides in the flow direclion where the solution gradients are small and their shorter sides normal to the surface to model steep solution gradients through the boundary layer thickness.
A second advantage is that the artificial dissipation required for the numerical stability. which could smear the solution gradients, can be controlled easily or turned off completely 16. Although the boundary layer thickness varles along the cylinder, the thickness $(\delta=0.06$ inches In Flg. 8) is assumed constant for the purpose of constructing the boundary layer mesh. Across the boundary layer thickness, 32 layers of gradualed quadrllateral elements are used with a geometric strelching lactor of 1.25. The thickness of the first element at the surface is $1 . \times 10^{5}$ inches and was chosen such that If should model the temperalure gradlent expected Irom the experimental heating rate 2 .

For general problems, the boundary layer thickness is not known and varles in the flow direction. An approach to estimale the boundary layer thickness using the fluld heal transler as the key parameler for remeshing has been proposed recently 10 . The approach is lllustrated In Flg. 9 . The boundary layer thickness, $\delta$, is estimaled from the absolute quantlty of the heat flux vector, $|\vec{q}|$, which is a maximum at the surlace and is Insignificant above the edge of the boundary layer. The size and distribution of the quadrilateral element layers are guided by the magnitude of the flow shearing stress ( $\tau_{x y}$ is proportional to $\left.\partial u / \partial y\right)$ which is a maximum at the cylinder surlace and decreases quadratically through the boundary layer thickness. Based on this idea, an adaptive remeshing technique using quadrilateral elements In the boundary layer can be constructed and combined with the current capability of the adapllve remeshing technique lor triangular elements in the Inviscid flow region.

To generate an integrated fluid-thermal-structural finite element model, the use of common nodes along the fluid/structure intertace is preferred 16 as highlighted in Fig. 10. This approach not only permils direct data transter between the different analysis disciplines but also provides consistency lor the analysis formulation. As an example of a coupled fluid/thermal problem, the interlace nodal temperalures can be obtalned by solving the coupled energy equation of the flow and the structure ${ }^{1}$ with the requirements that at the inierface: (1) the temperalures of the fluid and the struclure are Identical, and (2) the heat flux is conilinuous.

For some problems, the requitement of common fluid/structure interface nodes to preserve the mesh continuity may result in an excessive number of nodes in one of the disciplines. For example, a high stress concentration may occur near the fluid/structure Interface which may require a large number of the structural nodes even though the flow near that region is simple. Several adaptlve meshing technlques are leaslble for the thermal-sinctural analysis of the siruclure as indicated in Fig. 10 which Include the mesh refinementderelinement technique and the remeshing lechnique developed for the flow problems. Belore selecting one of these techniques, thelr effectlveness for thermal and structural problems must be evalualed. An Inilial evaluation of the adaptlve remeshing technique for both the thermal and structural analyses is pertormed in the next section.

\section{Convectlvely Cooled Leading Edge}

A 0.25-inch-dlameter convectively cooled leading edge subjected to intense aerodynamic heating is used to evaluate the adaptive remeshing technique for both the thermal and structural analyses, and to identify 
requirements lor the remeshing parameters for thermal stress problems. The example problem represents a hypersonic vehicle operating at Mach 16 whlch causes the vehicle nose bow shock to Intersect with the cowl leading edge bow shock. The Intersection produces the type IV supersonic jet interference pattern similar to that described in the first application. Because of the smaller leading edge dlameter and the higher Mach number conditions, the heating rate is very Intense with a peak of nearly 30,000 Blu/fit2-sec (see Ret. [1]).

The leading edge geomelry and boundary conditions are shown schemalically in Fig. 11. The outer surface is subjected to the aerodynamic heating and emits radiant energy to space. The Inner surface is convectively cooled by the direct Impingement of a sonlc hydrogen jet stream with an Inlel temperalure of $50^{\circ} \mathrm{R}$. The 1350 quadrilateral element mesh shown In Fig. $12(a)$ is typlcal of a structured mesh. The mesh has been used previously 1 for predicting transient thermalstructural response of the leading edge as the vehicle nose bow shock sweeps across during the vehlcle acceleration. The mesh is graded in the radial direction but is uniform in the circumferentlal direction. The leading edge material is assumed to be copper because of its high thermal conductivity. The copper material properties used in the analysis are highly temperature dependent and can be found in Rels. [17-18]. The predicted steady-stale leading edge temperature contours are shown in Fig. 12(b). The peak temperature of $766^{\circ} \mathrm{R}$ is at the jet impingement location where the heating rate is a maximum. In spite of the high thermal conductlvity of the malerial, the lemperature gradients are also high in this region. The problem is, therelore, suitable to be used for evaluating the adaptive remeshing technlque for the thermal analysis of the siructure.

The same adapllve remeshing procedure described for the flow problem is applied for the thermal analysis of the leading edge. A fairly unilorm mesh consisting of 885 triangles, shown in Fig. 13(a), is first constructed and the thermal analysis is performed to obtain the temperature distribution. Then the adaptive mesh shown in Fig. 13(b) is generaled using the temperature as the key parameter for remeshing to provide clustered elements in the region with high temperature gradients. The temperature distribution obtained from the second mesh is almost Identical (a difference of $0.2 \%$ ) to that obtained from the nonadaptive mesh shown in Fig. 12(b). However, the number of unknowns required for the adaptive unstructured mesh is reduce to about $25 \%$ of those used in the structured mesh. Note also that several elements are requlred through the thickness where the peak heating occurs and only one or two elements are required near the end of the leading edge. Hence, only an unstructured mesh technique would optimize the mesh.

To evaluate the effectiveness of the adaptive remeshing technique to represent both the thermal and mechanical stress fields, structural boundary constraints at the upper and lower leading edge sections are introduced. The Inner surface nodes at the constraint are fixed $(U=v=0$, see Fig. 14(a)) to simulate the consiraints caused by the Internal fins that support the leading edge from the inner primary structure. To highlight the remeshing capability for generating clustered elements in the regions needed, the rest of the nodes on both sections are constrained ditferently. These nodes are free to move on the upper section, but are constrained in the horizontal direction on the lower section. In addillon to the thermal loads, the leading edge is also subjected to mechanical loads from: (1) the aerodynamic pressure which has a distributlon similar to that shown In Fig. 5 but with a peak pressure of 1,000 psia, and (2) the unilorm internal coolant pressure of 1,000 psla.

The adaplive thermal mesh shown in Fig. 13(b) is used as the initial mesh for the structural analysis. The same analysis procedure is applied by first obtaining the structural analysis solution and then remeshing. In the remeshing process, nodal lemperalures of the new mesh are Interpolated from the nodal lemperatures of the thermal mesh shown in Fig. 13(b). For thermal siress problems, high stresses normally occur in regions of high temperature gradients. High siress concentrations may also occur at corners or supports even though the temperature is unilorm. Thus, to represent both the thermal stress and the stress concentration, key parameters for remeshing based on the temperature and the Von Mises stress are used. A new adaptive mesh generated by using these two remeshing parameters is shown in Fig. 14(a). Elements are clustered near the jet impingement location for modeling high thermal stresses from the high temperature gradients, and at the region near the upper support where the stress concentration occurs. The corresponding slructural response, based on a linear elastic behavior assumption, is shown by the clrcumferential stress contours superimposed on the deformed leading edge in Fig. 14(b). The ligure shows that a peak compressive stress of $25 \mathrm{ksl}$ occurs at the jet impingement localion and a high stress concentration occurs near the singular point at the upper support.

To support the Idea that the two remeshing parameters should be used simultaneously for generating an adaptive mesh for thermal stress problems, the same analysis approach is repealed but without using the temperature as the remeshing parameter. The adaptlve mesh generaled using the Von Mises stress alone as the remeshing parameler is shown In Fig. 15(a). Clustered elements are generated in the reglon near the upper support similar to the previous case. The mesh near the jet impingement localion is much coarser than the mesh for the previous case and does not resemble the mesh for the temperalure distrlbution. The corresponding predicted siructural response of the circumlerential stress contours is shown in Fig. 15(b). The contours are similar to those obtained in the previous case but are degraded due to the coarser mesh in the region of the jet impingement location. The difference between the peak compressive stresses of these two cases at the jet impingement location is approximately $15 \%$. Note that for thermal stress problems in which the structure is tree to expand, the thermal stress distribution normally resembles the distribution of the temperature. For such cases, the use of the Von Mises stress alone as the remeshing parameter may be adequate.

The adaptive remeshing technlque for the struclural analysis is further evaluated for the case in which the thermal load is not present. The leading edge is subjected only to the mechanical load which consists of the external aerodynamic pressure and the internal coolant pressure. The Von Mises stress is used as the remeshing parameter and the adaptlve mesh generated is shown in Fig. 16(a). Similar to the previous case, clustered elements are in the region near the upper support where the stress conceniration occurs. The corresponding predicted structural response of the circumferentlal stress contours is shown In Flg. 16(b). 
The predicted compressive siress of $5 \mathrm{ksl}$ at the jet Implngement locallon is much lower than the stress that occurred for the case with the thermal load. Obviously, superposition of the results for separate mechanical and thermal stress analyses would require interpolation of the results. Hence, the adaptive remeshing and analysis should be used for the combined load case.

For coupled fluld-thermal-struclural analysis, both the thermal and structural response of the leading edge affect the flow field. The flow field has to be updaled to include the ellects of: (1) the change of the leading edge surface lemperature, and (2) the leading edge deformation. The leading edge may delorm into or away from the Inillal flow fleld and updating the flow computational domain is necessary. The new flow fleld may govern reglons prevlously occupled by the leading edge where the flow information does not exist. These are some of the future issues which will be encountered and have to be clarified prior to applying the adaptive remeshing technique to coupled interdisclplinary problems

\section{Concluding Remarks}

An adapllve unstructured remeshing lechnlque was evaluated for integrated fluid-thermal-structural analysis. The technique generates an entirely new mesh based on the solution obtained from a previous mesh. The new mesh consists of clustered elements in the regions with high solution gradients and fow elements In the reglons where the gradients are small. The capabillty of the remeshing technique was demonstrated for the fluid, thermal, and structural analyses. The finite element formulallons used for the three discipllnes were presented. The basic idea behind the remeshing technique was described and the remeshing indicators and requirements were idenlifled.

Two appllcations were presented to essess the effectiveness of the remeshing technique. The fluld analysis of Mach 8 shock-shock interference on a three. inch-diameter cylinder was used as the first application to Illustrate the remeshing technique for complex flow and to investlgate the meshing issues for the integraled fluid-thermal-structural analysis. Fluld density was used as the remeshing paramivier lor generating adaptive trlangular elements in the inviscid flow region. In the current procedure, layers of quadrilateral elements are constructed in the boundary layer to represent accurate aerothermal loads. The predicted aerodynamic pressure and heating rate are in good to fair agreement with the experimental data. An approach for generating an adaptlve structured mesh of quadrilateral elements in the boundary layer was described. The approach can be combined with the current adaptive unstructured remeshing technique used in the inviscid reglon to achieve an automated remeshing capability for the entire flow domain.

The remeshing technique was extended to the thermal and structural analyses of the structure. The applicability of the technique to thermal stress problems was demonstrated with a 0.25 -inch-dlameter convectively cooled leading edge subjected to intense aerodynamic heating. Temperature was selected as the remeshing parameter In the thermal analysis so that clustered elements are generated in regions of high temperature gradients. The technique provides the same temperature solution accuracy compared to a relined structured mesh but with a significant reduction
In the number of unknowns. For the structural analysis of the leading edge subjected to both thermal and pressure loads, remeshing paramelers of the temperature and the Von Mises stress are used to provide clustered elements in reglons of high thermal and mechanical stresses as well as reglons with a stress concentration.

The results from the appllcatlons have demonstrated the vlability of the adapllve unstructured remeshing technique combined with the finite element methods to provide efflclent accurate solutions to complex flow-thermal-siructural behavior.

\section{Aelerences}

1. Dechaumphal, P., Thornton, E. A. and Wieting, A. A., "Flow-Thermal-Structural Study of Aerodynamically Heated Leading Edges," AlAA Journal of Spacecratt and Hockeils. Vol. 26, No. 4, July 1989, pp. 201-209.

2. Wieling, A. R., "Experimental Sludy of Shock Wave Interference Heating on a Cylinder Leading Edge," NASA TM-100484, May 1987.

3. Pamakrishnan, R., Bey, K. S. and Thornton, E. A., "An Adaptive Quadrilateral and Triangular Finite Element Scheme for Compressible Flows," AIAA Paper No. 88-0033, January 1988.

4. Thornton, E. A. and Dechaumphai, P., "Adaptlve Refinement for Ellective Finite Element Thermal and Structural Analyses," International Conterence on Accuracy Estimates and Adaptive Refinements In Finite Element Computations, Lisbon, Portugal, Vol. 2, 1984, pp. 65-74.

5. Lohner, R., Morgan, K. and Zienklewicz, O. C., "Adaptive Grid Refinement for Compressible Éuler and Navler-Stokes Equalions," International Conference on Accuracy Estimates and Adaptive Refinemenis in Finite Element Computatlons, Lisbon, Portugal, Vol. 2, 1984, pp. 189-202.

6. Morgan, K., Peraire, J., Thareja, R. R. and Slewart, J. R., "An Adaplive Finite Element Scheme for Euler and Navier-Stokes Equatlons," AIAA Paper No. 87-1172, June 1987 .

7. Peraire, J., Vahdall, M., Morgan, K. and Zlenklewicz, O. C.," Adaptive Remeshing for Compressible Flow Computalions," Jeurnal of Computational Physlcs, Vol. 72, 1987, pp. 449-466.

8. Dechaumphal, P. and Wieling, A. R., "Coupled Fluld-Thermal-Structural Analysis for Aerodynamically Heated Siructures," Finite Elemenl Analysjs in Fluids, Edited by Chung, T. J. and Karr, G. R.. The University of Alabama in Huntsville Press, April 1989, pp. 165-171.

9. Dechaumphai, P., Wieting, A. R. and Pandey, A, K., "Fluld-Thermal-Siructural interaction of Aerodynamically Heated Leading Edges," AIAA Paper No. 89-1227-CP, Aprll 1989.

10. Vemagantl, G. R., "An Adaplive Remeshing Finite Element Method for High Speed Compressible 
Flows Using Quadrilaleral and Triangular Elements," Ph.D. Dissertation, Old Dominion University, May 1989.

11. Pandey, A. K., Dechaumphal, P. and Wieling, A. R., "Thermal-Structural Finite Element Analysis Using Linear Flux Formulation," AIAA Paper No. 891224-CP. April 1989.

12. Gnoffo, P. A., "Applicalion of Program LAUAA to Three-Dimensional AOTV Flowlields," AIAA Paper No. 86-0565, January 1986.

13. Oden, J. T. and Carey, G. F., Einite Elements: Mathematical Aspects. Prentice-Hall, Englewood Clilis, 1981.

14. Holden, M. S., Wieting, A. R., Moselle, J. R. and Glass, C., "Study of Aerothermal Loads Generated in Region of Shock/Shock Interaction in Hypersonic Flow," AlAA Paper No. 88-0477, January 1988.

15. Holcomb, J. E., Curtis, J. T. and Shope, F. L., "A New Version of the CVEO Hemisphere Viscous Shock Layer Program for Equilibrium Air," Arnold Engineering Development Center. Arnold Air Force Station, TN, AEDC-TMR-85-V7, February 1985.

16. Thornton, E. A. and Dechaumphal, P.. "Coupled Flow. Thermal, and Structural Analyses of Aerodynamically Heated Panels," AlAA Jeurnal of Aircraft. Vol. 25, No. 11. November 1988, pp. 1052 1059.

17. Touloukian, Y. S., Powell, R. W., Ho, C. Y. and Klemens, P. G., "Thermal Conductivily for Melallic Elements and Alloys," Thermophysical Properties ofMatters. Vol.1. IFI/Plenum, New York, 1970. pp. 68-81

18. Metals Handbook Committee: Melal Handbook. Eight Edition, American Society for Metals, Ohio, 1975.
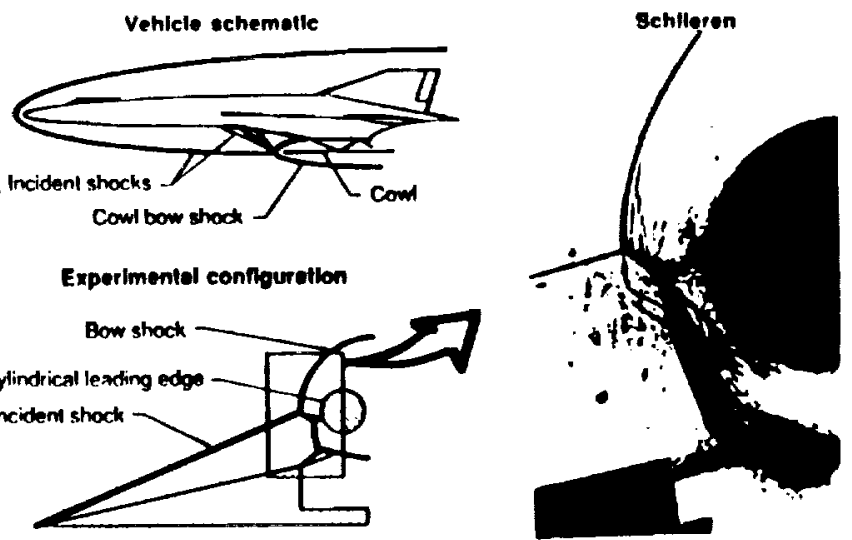

Fig. 1 Vehicle schematic, experimental configuration, and schlieren of type IV shock-shock interference.

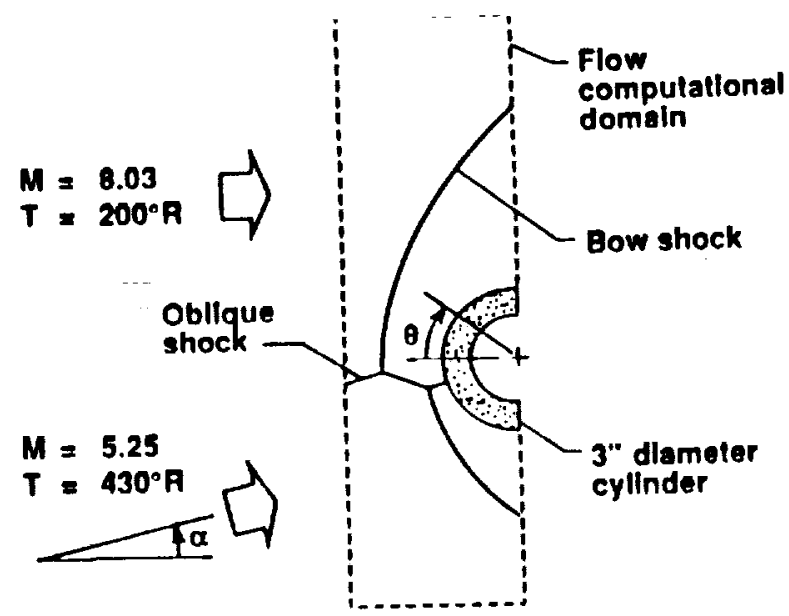

Fig. 2 Oblique and bow shock inleraction pattern lor Mach 8 shock-shock interference on a threeinch-diameter cylinder.

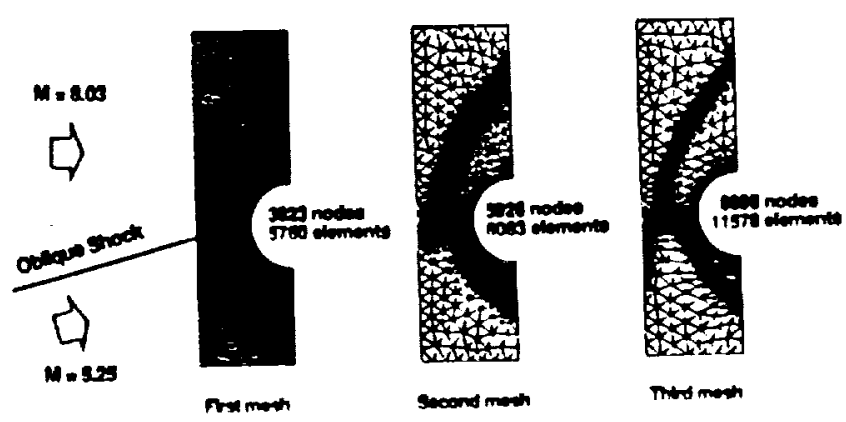

Fig. 3 Adaplive linite element mesh evolulion of the flow domain for Mach 8 shock-shock interterence on a three-inch-diameter cylinder.

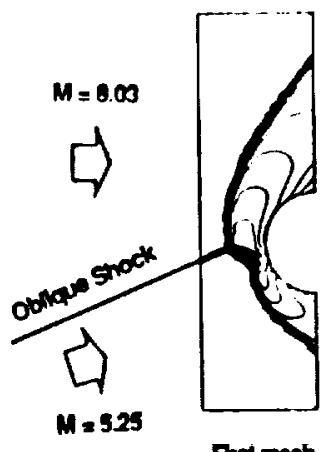

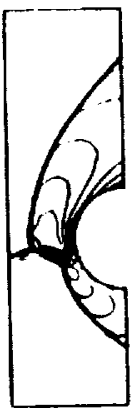

sicond mesh

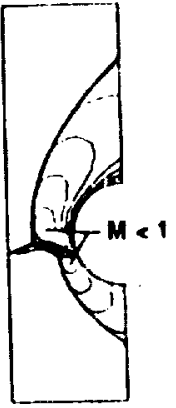

Thrd mesh
Fig. 4 Flow Mach number contours for the three adaptive unstruclured finite element meshes for Mach 8 shock-shock interlerence on a threeinch-diameler cylinder. 


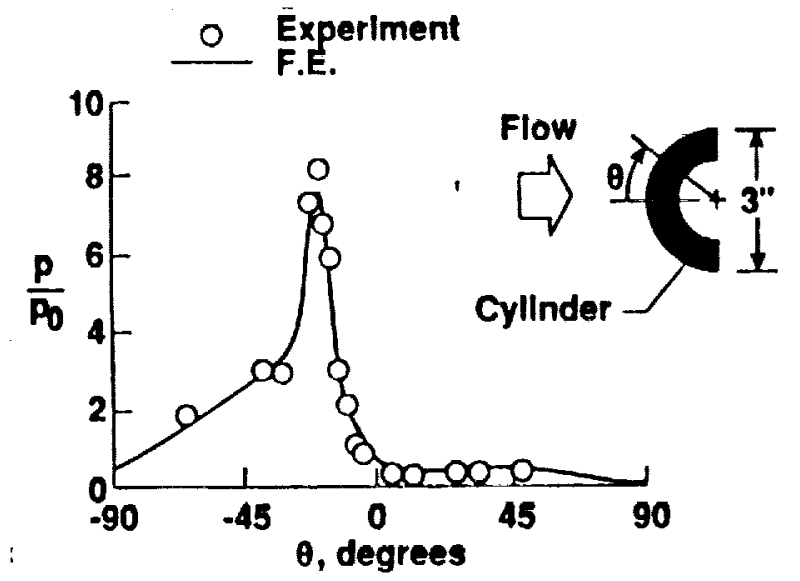

Fig. 5 Comparison ol surface pressure distributions on a three-inch-diameler cylinder subjected to Mach 8 shock-shock Interference.

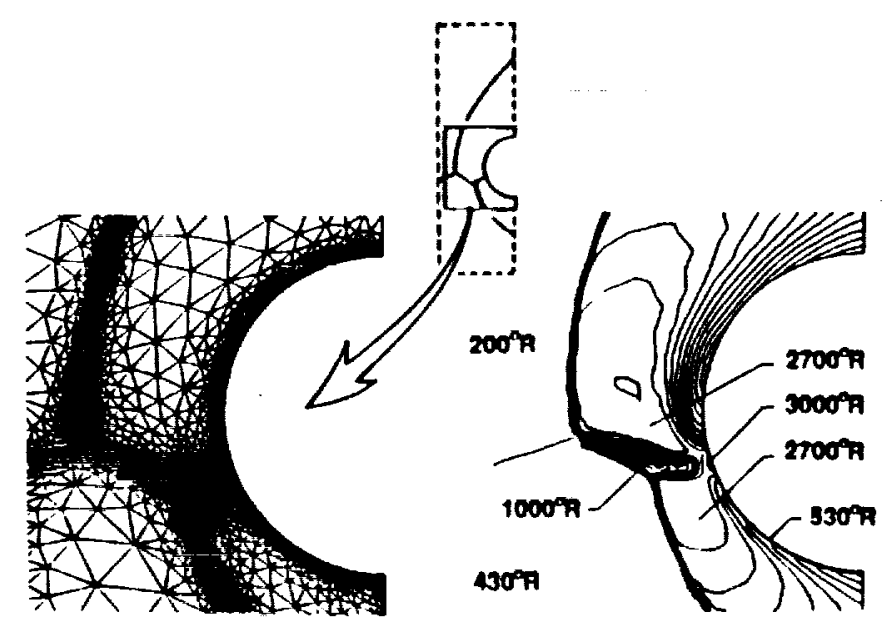

Fig. 6 Detalls of the finite element mesh and fluid temperature contours in the Interaclion region for Mach 8 shock-shock interference on a threeinch-diameter cylinder.

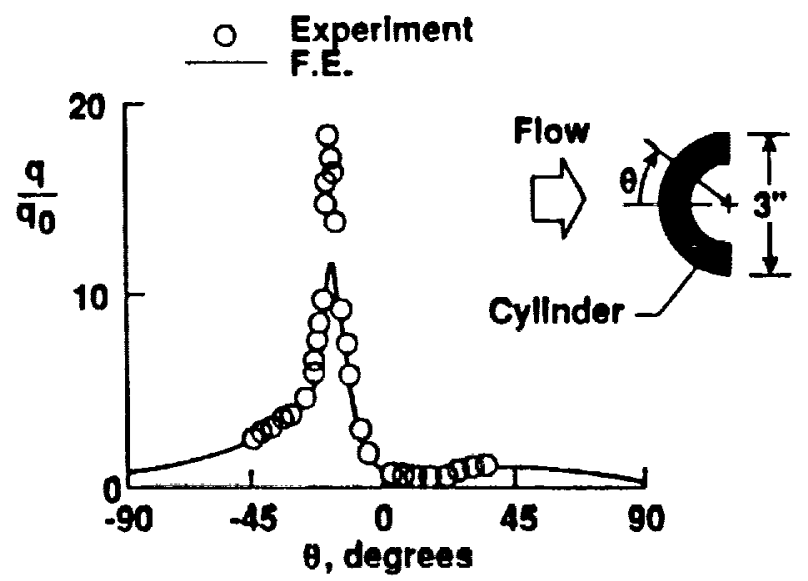

Fig. 7 Comparison of surface heating rate distributions on a three-inch-diameter cylinder subjected to Mach $B$ shock-shock interference.

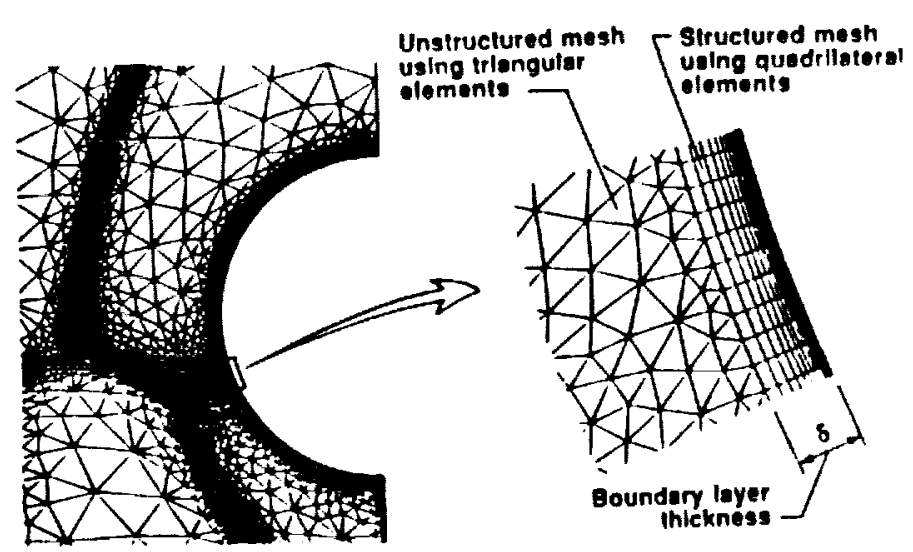

Fig. 8 Details of the finite element mesh in the interaction reglon and layers of quadrilateral elements in the boundary layer.

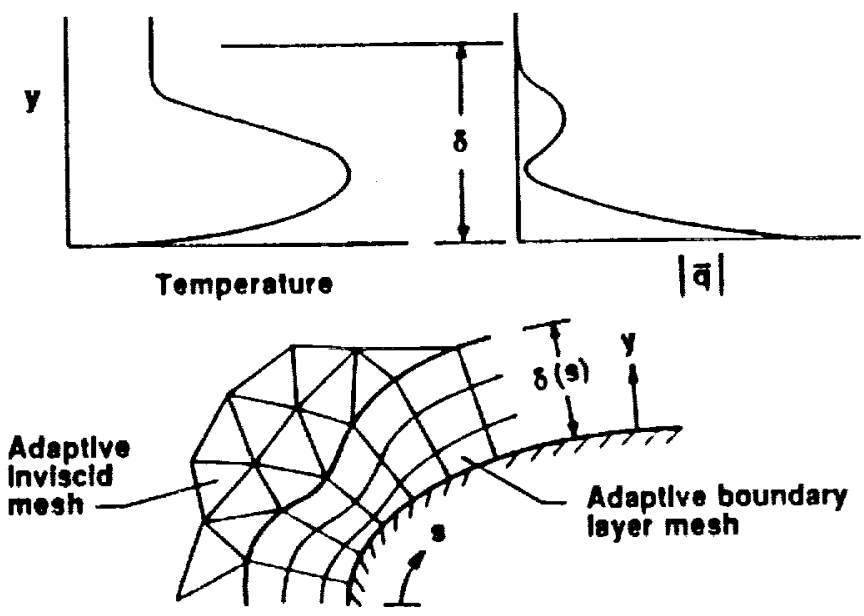

Fig. 9 Typical temperature and absolute heat flux vector distributions in the boundary layer and adaptive boundary layer mesh with quadrilaleral elements.

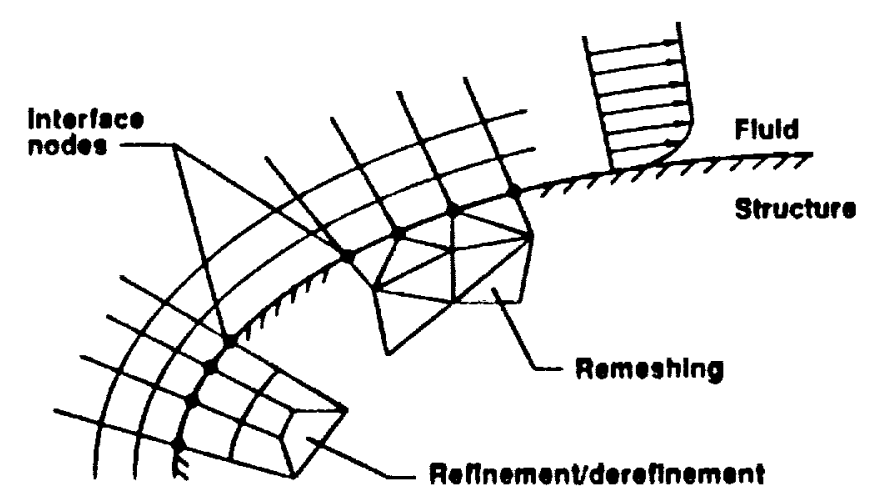

Fig. 10 Integrated fluid-thermal-structural mesh concap: and adaptive meshing optlons for thermalstructural analysis of the structure. 


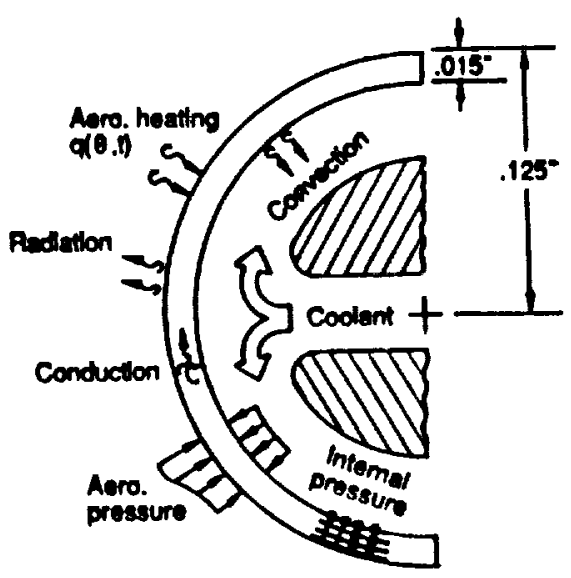

Fig. 11 A schematic thermal-struclural analysis model of 0.25 -Inch-diameter leading edge with boundary conditions.

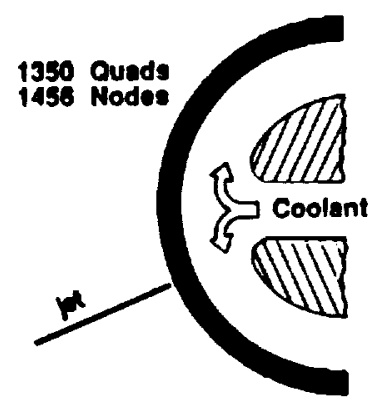

(a) Nonadaptive structured mesh

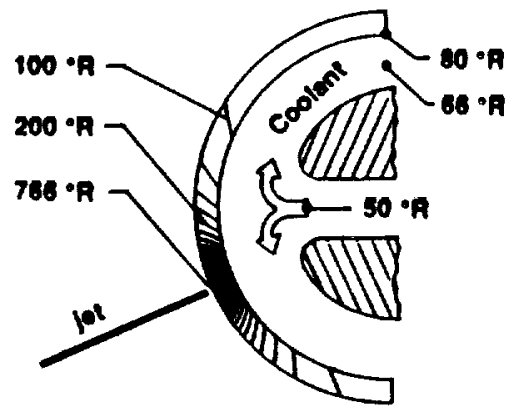

(b) Temperalure contours
Fig. 12 Nonadaptive finite elemenl mesh and temperalure contours for convectively cooled leading edge.

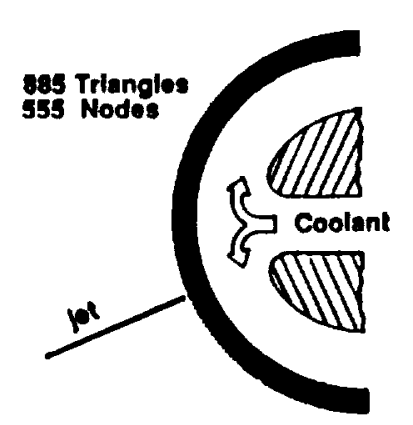

(a) First mesh

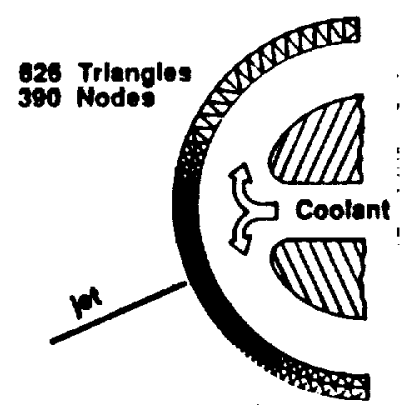

(b) Second mesh
Fig. 13 Adaptive linite element mesh evolution for thermal analysis ol convectively cooled leading edge.

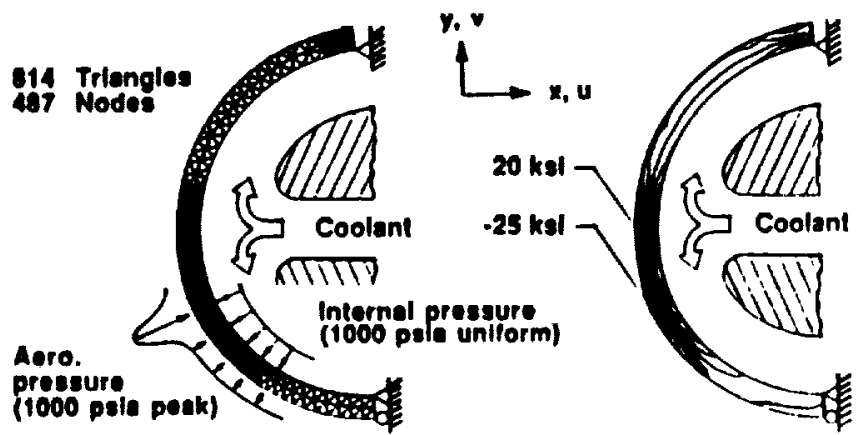

(a) Adaplive mesh

(b) Circumlerential stress

Fig. 14 Final adaptive mesh and circumferential siress for convectively cooled leading edge sublected to thermal and pressure loads.

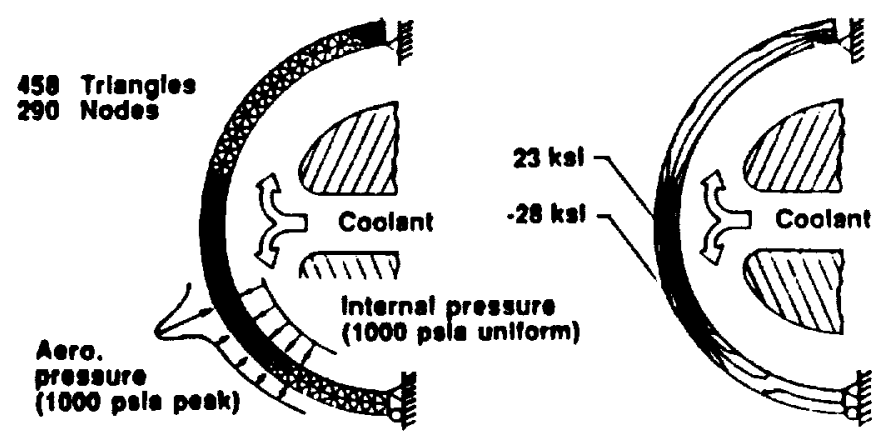

(a) Adaplive mesh

(b) Circumferential stress

Fig. 15 Adaptive mesh using Indicator of Von Mises stress and circumlerential stress lor conveclively cooled leading edge subjecled to thermal and pressure loads.

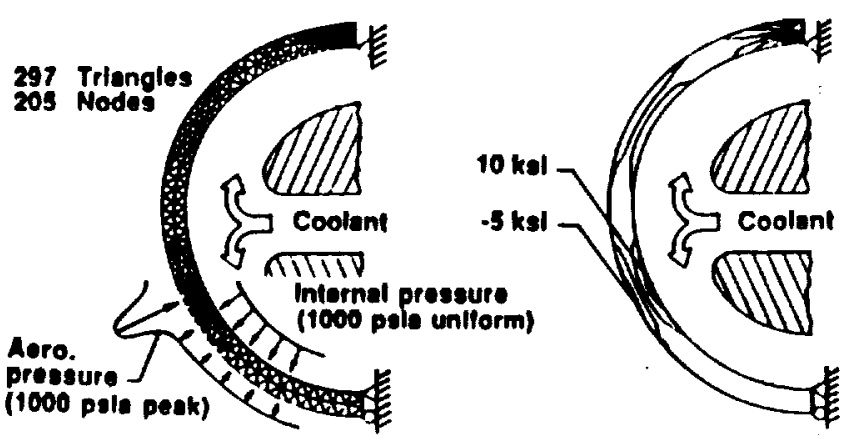

(a) Adaptive mesh

(b) Circumferential stress

Fig. 16 Final adaplive mesh and circumferential slress for convectively cooled leading edge subjected to pressure load. 


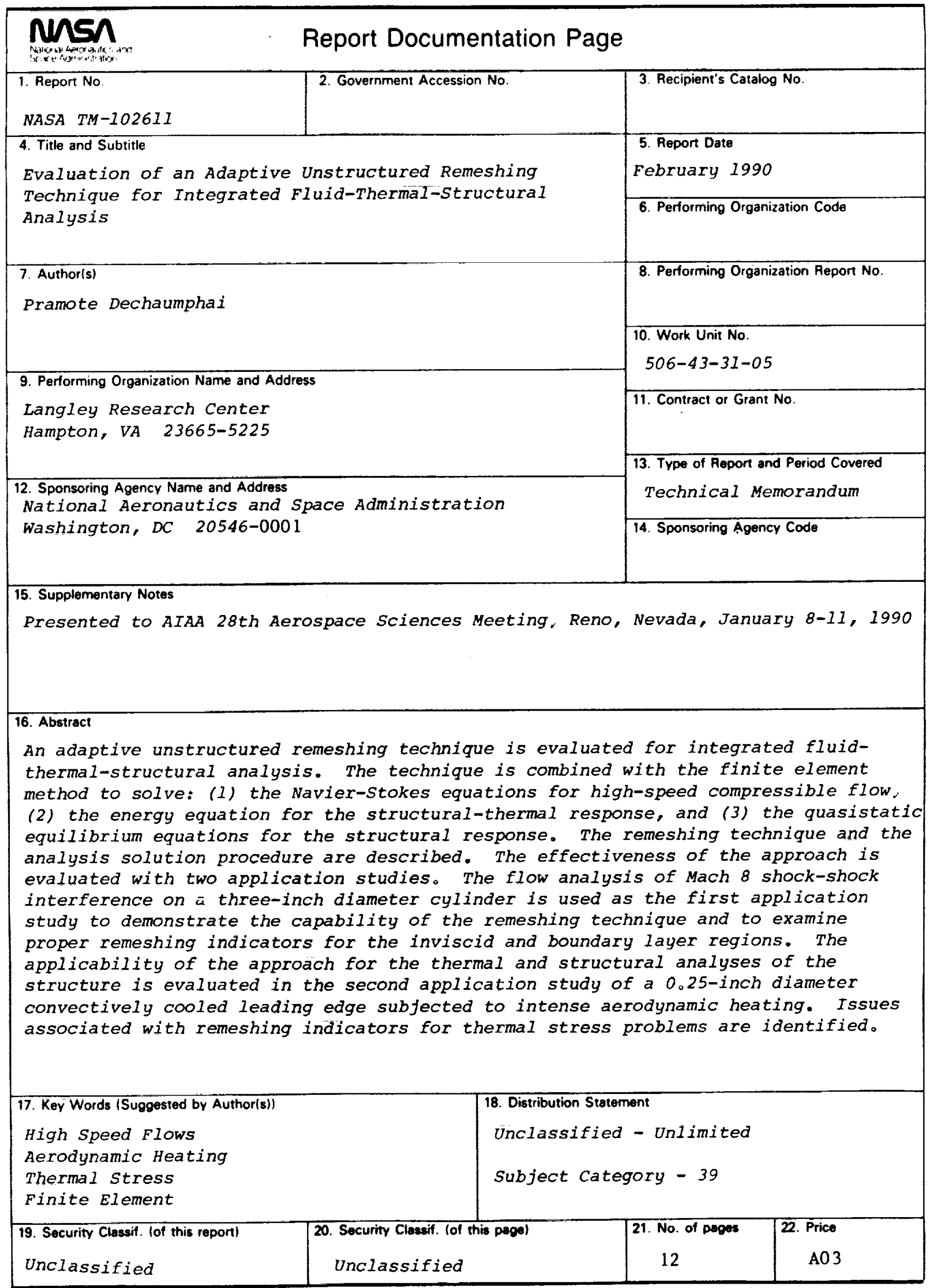

NASA FORM 1020 OCT 66 